\title{
Towards an Economic Theory of the Church
}

Economic

Theory of the Church

\author{
by \\ Brooks B. Hull \\ University of Michigan-Dearborn, and \\ Frederick Bold \\ Criterion, Inc., Irving, Texas, USA
}

\section{Introduction}

Religion is one of the most pervasive phenomena in the human experience. Since virtually all societies throughout history engage in religious activity, it is surprising that economists give religion only limited attention. While the economic literature on religion is not very broad, it is long, dating back at least to Adam Smith. Smith even anticipates the important theme in this article that the church can be treated as a firm: "The clergy of every established church constitute a great incorporation"' 1 , p. 207]. Another important branch of scholarship, of which works by Tawney $[2]$ and Weber $[3]$ are major contributors, attempts to explain the effect of religious doctrine on the evolution of economic thought and behaviour, but fails to apply economic theory to religion itself.

Recent economics research avoids the central issue of the nature of religion itself, and instead focuses on the effects of religion on various aspects of behaviour. Meng and Sentance [4] and Tomes[5] explore the impact of religion on individual earnings using US data. Also limiting themselves to US data, Ehrenberg[6] and Long and Settle [7] analyse factors influencing church attendance. In a humorous article, Dixit and Grossman [8] show how a limited number of positions in heaven result in rentdissipating activity. More recently, Posner[9] uses economic analysis of the law to predict its effect on religion in the United States.

Economics offers an appealing apparatus with which to analyse the church and religion: the theory of the firm. The theory's potential insights in analysing the church have been acknowledged by other disciplines. Stark and Bainbridge[10], for example, use an "entrepreneur model" as one method of explaining the formation of sects and the behaviour of their founders.

The notion that the church can be viewed as a firm points toward two directions for enquiry. The first, the subject of the next section, concerns the intrinsic nature of the church. Here, we assert that the church serves the unintentional but essential function of reducing transactions costs primarily by enforcing a system of property rights.

The authors would like to thank Larry Blume, Keith Leffler, Eugene Silberberg and discussants at a session of the Western Economic Association meetings for comments on drafts of this article. We remain responsible for errors and omissions. 
International Journal of Social Economics 16,7
The second direction for enquiry is to apply standard neoclassical theory of the firm to the church. We suggest that the church produces four sets of products which serve the combined functions of helping to enforce property rights and earning revenue for the church. We then test implications of the model using cultures from the Human Relations Area Files.

\section{The Nature of the Church}

Given the regularity with which churches exist and endure in human societies despite the great variety in religious doctrine, it appears that churches and religions play a role in society separate from the question of cosmological truth. Indeed, the survival of the church and religions is subject to the guidance of Adam Smith's invisible hand and by the process of natural selection outlined by Becker[11, p. 282] and Alchian[12]. Institutions such as the church - to paraphrase Smith may be guided by an invisible hand to promote an unintended end.

The essential and unintended function of churches and religion, we contend, is the reduction of transaction costs. This is accomplished primarily through establishing and enforcing a system of property rights. Further, if situations in which changes in the relative costs of alternate property rights enforcement methods (or changes in relative benefits) are identified, we can test whether the implied change in enforcement method actually takes place.

Throughout history, religions and churches have been a central force in creating and perpetuating rules of behaviour. Religions invariably include, as part of their doctrine guidelines, rules like the Ten Commandments. These are the foundation of a property rights system and thereby facilitate individual maximising behaviour. They also reduce transactions costs by supplying standard-form contracts.

For example, religious rules commonly define the distribution of property and labour at marriage. Other religious standards define legal and illegal appropriation of property. More generally, religious rules reduce the cost of the whole universe of social interaction by providing a consistent set of behavioural standards to members of a culture, a notion recognised by authors, including Cheung[13] and Posner[14].

Another pervasive feature of religion is, of course, concern with matters beyond the earthly vale. A plausible explanation of this aspect is that religion is a primitive science and serves a human need for explanation of matters beyond ordinary understanding. Although satisfaction of curiosity is clearly a valuable product, gods, heaven, and hell also represent an important innovation in property rights enforcement.

Religions regulate behaviour by instilling the expectation that improper actions are met with divine retribution and that proper actions are rewarded. Of course, churches have used temporal methods of behaviour enforcement like incarceration, torture and execution, but, in general, it should be clear that religion provides a set of property rights enforcement instruments distinct from those used by secular authority.

Declines in the cost of secular enforcement should reduce the role of the church in property rights enforcement. For example, the marginal cost of secular property rights enforcement is low in a country with a large standing army to deter alien 
armies and ensure domestic tranquility. Henry VIII is reputed to have been an exceptional military and civil leader, exactly the requirements necessary to supplant the Pope's authority. North and Thomas[15] explore the importance of technological developments which alter the relative costs of non-religious methods of enforcement

The relative advantage of secular enforcement increases as wealth increases. Increases in individual wealth mean there is more for secular authority to take away as punishment for breaking laws. Similarly, the loss of eternal life is relatively less important for a rich person than for a poor person. Also required is that individuals cannot take wealth with them at death. In religions where wealth is carried into death, religious authority maintains the threat of damnation in the face of increasing income. The strength of the Egyptian theocracy is an example.

Property rights enforcement by religion is not without difficulty, however. Since property rights enforcement is a public good, the supplier is confronted with the problem of charging and collecting for services provided. We suggest that, in general, it is too difficult for the church (or secular authority) to charge directly for this product, so income must be earned in some other way (secular authority uses involuntary taxation). The church solicits donations and also markets nonpublic goods and services. At least some of the income from these activities is used to support the costs of providing property rights enforcement and other public goods. Because the church markets non-public goods and must maintain positive net revenue, the theory of the firm may be applied directly to the church.

\section{Churches and Wealth Maximisation}

The fundamental behavioural postulate of the theory of the firm is that firms maximise wealth. Economists have good reason to expect that the assumption of wealth maximisation leads to reliable explanations and predictions. For one, the continued survival of any institution requires it to face the possibility of bankruptcy. To continue to operate, an organisation must maintain earnings at least equal to opportunity cost. Organisations that survive over time are necessarily those that have been able to maintain non-negative net revenue.

A possible objection here is that in societies with a single church, or a government-supported church, the absence of competition between churches means a church is not obliged to maximise. The response to this argument is that, although it may face no competition from existing churches, the church faces competition from secular organisations in at least some markets and faces the threat of entry by new religions. Further, both firms and churches compete for the same resources and are therefore forced to manage their activities efficiently.

Wealth maximisation is consistent with church behaviour, but this alone does not account for the church's distinct and enduring characteristics. A more general notion of wealth maximisation is appropriate. In light of Stigler's survivorship principle[16], the durability of religion in human societies strongly suggests that churches provide valuable products that aid in the continued survival of the society itself.

\section{Church Outputs}

Firms tend to sell a particular set of products because doing so maximises profit by reducing information costs to consumers and takes advantage of specialisation, 
International Journal of Social Economics 16,7

8 economies of scope, and gains from tied sales. Churches also provide a particular set of products, because doing so maximises net benefits. This product mix is determined primarily by the basic function of the church and religion - reduction of transaction costs - and by demand for complementary products. In this article, these products are grouped in four classes labelled temporal bliss, social goods, deferred perpetuity and altered fate.

The last of these is only briefly mentioned here. Churches commonly offer methods to alter what otherwise might be considered uncontrollable events. Intercession, laying on of hands and some kinds of prayer are all designed to influence the future. In providing this product, the church uses techniques like those modelled in subsequent sections of the article. In addition, the church's ability to sell altered fate is affected by alternative sources, primarily scientific knowledge.

\section{Temporal Bliss}

Temporal bliss is a set of products that bring happiness in this vale. These products are traded in other markets and include goods like fellowship and entertainment. The benefits to the church of providing these products are straightforward. Temporal bliss provides a source of revenue, it helps expand church membership (in turn enhancing revenue), and it provides an appealing and effective vehicle for communicating church doctrine.

Because it is only one of many possible producers of temporal bliss, the church has an incentive to create and enforce a monopoly. Churches engage in a number of activities that have the effect of monopoly maintenance. Churches from time to time proscribed dancing, alcohol, gambling, dating, movies, make-up and video games, all forms of entertainment available outside the church. In at least one case, a church successfully promotes an activity within the church and discourages the same activity outside it, even managing to obtain state enforcement: bingo gambling. To the extent that such restrictions are successful, the church maintains its position as sole producer of entertainment.

As personal income increases and entertainment technology improves, entry by competing producers of temporal bliss becomes more likely. Entry of substitutes to church entertainment causes predictable changes in church behaviour. Churches must increase quality or reduce the price of products they offer. They begin to advertise. Church buildings become more architecturally stylish. Services are offered at more convenient hours, take less time, and contain greater entertainment content.

\section{Social Goods}

The second class of church products are public goods and include social rules and some important group activities. This article addresses property rights enforcement, the most important and pervasive social good, but religions provide other public goods as well, examples being preservation of knowledge, some kinds of scientific research, education and dispute mediation. Two additional examples of church-supplied social goods are discussed in more detail here: income redistribution and health rules. 
Church members are encouraged to engage in charitable activities directly or to donate money to support charitable activities organised by the church. One reason churches encourage this sort of income redistribution follows the central theme of this article. Income redistribution can be a cost-minimising method of protecting property rights, in this case by reducing the incentive for theft by those who are poor enough so that legal or moral prescriptions against theft are ineffective.

Income redistribution can ameliorate this problem. The legal system is freed of the difficulty of prohibiting an activity to which some people have little alternative. Recipients of redistributed income are given a lower cost alternative to theft and suppliers of redistributed income (potential crime victims) benefit both from the lower cost of coercive property rights protection and from a lower variance in income.

If suppliers of income are averse to risk, income redistribution acts like insurance. As with ordinary insurance, the insured are willing to allow insurance companies (in this case the church) to appropriate some share of donated funds. The church enhances its financial position to the extent it retains these funds.

Another form of church-provided insurance occurs because income redistribution reduces the variance in individual income due to unforeseen misfortune like crop failure and disease and, to some extent, foreseen events like relative poverty in old age. Once again, the insured are willing to allow the church to appropriate a share of donated funds.

A second example of a social good provided by the church is the common imposition of various rules of cleanliness, medical treatment, food preparation and sanitation. The benefit to society of such rules is obvious. All members of a society gain by engaging in activities that reduce the possibility of the spread of disease. Kosher food rules are an excellent example of church rules whose effect is arguably to assure proper nutrition and reduce the spead of disease. One implication here is that, ceteris paribus, regions with greater population density or greater tendency to support disease should have churches with more extensive health rules than other regions.

The preceding discussion describes important products produced by religions but does not explain what advantages the church has over government or ordinary private markets in providing the products. As mentioned, the social goods described here are public goods. For example, an individual engaging in good health practice is directly better off because of the reduced probability of disease, but all other members of the community also benefit since the given individual is less likely to spread disease to them.

In private markets, public goods production faces obstacles not found in the production of other goods. Producers have difficulty appropriating the value of the goods to others and so are less inclined to produce them. However, in some situations, the church possesses characteristics that give it a comparative advantage in encouraging production of certain public goods.

As Posner[14] shows, members of very small communities recognise the social costs of disease and poverty and are more inclined to act to reduce them. These cultures rely on extended family groups and practise forms of communal behaviour in which wealth sharing is an explicit part of the organisation. Here organised religion has no special advantage. 
International Journal of Social Economics 16,7
In larger communities, people are less likely to recognise the social cost of individual misbehaviour and are less likely to behave properly since any one person's gain from proper behaviour is so much smaller than the social gain. Community size is large enough for interaction to take place outside family groups but interaction is not extensive enough to include personal contact with all community members. Here, religious requirements assure provision of valuable social goods, and these cultures should possess the strongest organised religions. Homans[17] shows the Medieval Catholic Church's role in enforcing appropriate behaviour in larger communities. Davies[18] does the same for the Mormon church.

By similar reasoning, organised religion is relatively less effective in industrial states. Here, the power of the central government to enforce property rights, transfer income and assure other proper behaviour eclipses the church's abilities.

Given that it has a comparative advantage in encouraging particular social behaviour in some societies, by what methods does the church enforce its wishes? In addition to methods available to temporal authority, religions have two enforcement tools: the threat of social ostracism and the threat of punishment after death.

An implication of the above is that cultures that rely heavily on church enforcement of property rights should include both heaven and hell as part of their doctrine. These two extremes represent the maximum potential reward for good behaviour. In other research, Hull[19] shows how Roman Catholic Church doctrine on heaven, hell and purgatory changed in the High Middle Ages in a manner implied here.

In cultures with state enforcement of property rights, the threat of hell to encourage particular behaviour is relatively less important. In these cultures, therefore, religions are more likely to assert there is no hell and that heaven is achieved automatically or is preordained.

Generally, firms prosper by offering products that are valuable to consumers. Hell is not valued by consumers (by definition). Its use, however, does increase church revenue and serves a valuable function to society. To the extent that hell enforces appropriate behaviour, it assures both the society's and the church's prosperity and viability.

\section{Deferred Perpetuity}

The third class of products offered by the church is a special form of a deferred perpetuity: blissful eternal life after death. A desirable external life is a common feature of religions. This product has one essential aspect in common with other products - it is available for a price. In some cases, like the common payment for indulgence at one time in the Roman Catholic Church, direct money payment to obtain heaven (more quickly) was used. However, direct payment for a desirable versus an undesirable eternal life is by no means the dominant feature of religious teaching. More often heaven is acquired by adopting certain beliefs or by engaging in certain actions.

Following one theme of this article, a church's choice for heaven's price is in general that which maximises net benefits and addresses potential competition from other organisations. To the extent that people modify their behaviour, the property rights system is protected. When the church does extract money payments for heaven, non-revenue producing functions can be subsidised. 
From the standpoint of economic theory, the product eternal life is particularly interesting because it is a credence good. The term credence good was coined by Darby and Karni[20] to label goods that have characteristics that cannot be determined either before or after purchase. Goods with credence attributes are a sub-group of the search goods introduced by Nelson[21].

The sale of credence goods presents interesting problems. Since a good's characteristics cannot be determined before or after purchase, a buyer must rely on the seller or a third party expert to provide information about the good. Unfortunately, sellers of credence goods have incentives to cheat consumers by overstating the product's merits (and so raise its price). Further, information from a third party expert is also a credence good.

Buyers and honest sellers of credence goods gain if honest sellers can somehow assure their honesty. In the case of external life, the church may not be able to prove the existence of life after death, however, it can assure consumers that priests sincerely believe in life after death and believe that certain steps must be taken to achieve it.

As a first step in assuring priestly sincerity, the church can reduce the potential personal gains to priests from the sale of eternal life. If successful, priests will be disinclined to misrepresent doctrine and exploit believers. For example, priestly vows of poverty and low fixed priestly pay scales help assure church honesty. Similarly, priests are often allowed to use but not own church facilities and housing.

The common requirement of priestly celibacy also encourages honesty by priests since celibate priests cannot pass wealth to heirs. Interestingly, celibacy has not always been a requirement of Roman Catholic priests but was adopted in 1215 $\mathrm{AD}$ in part as a response to priestly abuses.

Protestant churches did not enforce celibacy. When formed, these churches had no store of valuable assets to lose and faced competition for priests from the existing church and other newly formed churches. In addition, the Protestant churches had little to offer potential priests and so chose to attract them by relaxing the celibacy requirement.

The activities of church members also reduce the incentive by priests to misrepresent doctrine. When they engage in volunteer activities or other good deeds, members are transferring assets in a form that cannot be misappropriated by the church. This practice helps assure church and priestly honesty and makes participants and recipients better off, even though cash payments might appear to be a more efficient method.

Even church architecture can help guarantee church integrity in selling heaven. A cathedral is a sheltered location for services and a dramatic advertisement, but the ornate structure and unique symbols built inseparably into the structure also mean that the cathedral fits Klein and Leffler's description of nonsalvageable capital used to assure product quality[22]. This substantial longlived investment with little or no salvage value signals church members that the church has made a substantial long-term commitment to maintaining customers' satisfaction. Should it fail to serve members, the church forfeits the investment in the cathedral. 
International

Journal of Social

Economics

16,7
As an implication, churches which do not rely on expert priests should be less likely to feature ornate cathedrals or other facilities. Consistent with this implication, Quaker meeting houses are highly salvageable, often having been converted from some other use.

\section{Empirical Results}

The model yields a number of implications, some of which are amenable to statistical analysis. The Human Relations Area Files (HRAF) provides a unique opportunity to test the model. It is a detailed index and system of cross-referencing 700 categories of information from ethnographies written by anthropologists about more than 300 cultures.

Some of this textual material has been coded by sociologists and anthropologists, the first important example being the Ethnographic Atlas[23]. Subsequent researchers have coded material for a subset of 186 cultures in the HRAF. The subset is labelled the Standard Cross-Cultural Sample and its cultures are chosen according to a variety of criteria including that all cultural types be represented, that territories not overlap and that relatively comprehensive information be available [24, 25].

Table I summarises a series of multinomial probit equations with variables from the HRAF that correspond to some of the implications of the theory. The independent variable Gods measures on a scale of one through three the degree to which high spiritual beings who created reality are active and supportive of human morality in the culture[23].

Hierarchy measures from one through four the levels of political jurisdiction above the local community. H-Square is the square of Hierarchy, and is included because the model predicts a concave relationship between Gods and Hierarchy. Crafts indicates the extent of specialised technical skills in the culture and is ranked from zero to four. These variables were coded by Murdock and Provost[26].

Sects indicates on a scale of one through four the number of sects and religions in the culture. The code does not account for similarity of religious doctrine in different religions. This variable was coded by the authors.

Credit ranks on a scale of one through four the extent and efficiency of banking and credit in the economy[27]. The variable Temples equals one if the most impressive structure in the community is a temple, church, or other religious structure. Otherwise, the variable is zero. This variable was adapted from a measure coded by Murdock and Wilson[28].

The variable Hierarchy measures the general complexity of the society. The coefficients on the first two independent variables show that the power of religion increases and then decreases as a society becomes more complex. This is consistent with the model. The church is most influential in complex societies without a fully developed central government.

Church influence and craft specialisation are also positively related. This is consistent with the model to the extent that Crafts indicates the degree of specialisation in priestly skills as well. The number of sects and religious influence are positively related. Sects tend to serve a variety of individual interests and so increase the power of the church. 


\begin{tabular}{|ccccccc|}
\hline Equation & Hierarchy & H-Square & Crafts & Sects & Credit & Temples \\
\hline$(1)$ & 1.46 & -0.29 & 0.20 & 0.21 & 0.21 & 0.02 \\
& $(3.24)$ & $(3.03)$ & $(2.10)$ & $(1.72)$ & $(1.68)$ & $(0.08)$ \\
$(2)$ & 1.46 & -0.29 & 0.20 & 0.21 & 0.21 & - \\
& $(3.24)$ & $(3.03)$ & $(2.11)$ & $(1.72)$ & $(1.69)$ & - \\
$(3)$ & 1.37 & -0.27 & 0.18 & - & 0.14 & - \\
& $(3.65)$ & $(3.36)$ & $(2.16)$ & - & $(1.24)$ & - \\
$(4)$ & 1.48 & -0.28 & 0.20 & - & - & - \\
\multicolumn{7}{l}{ Numbers in parentheses are the ratio of coefficients and asymptotic standard errors. These } \\
are distributed normally for "large" samples. Sample size is 128.
\end{tabular}

To the extent that credit markets are efficient, the variance in available interest rates falls. Lenders demand lower average interest rates when such risk is reduced. Lower interest rates mean that the present value of heaven is greater as is the present cost of hell. The church has more influence in this case.

The presence of cathedrals or temples as the most dominant community structure has no significant influence on church power in the sample. The measure itself is not without fault, as it only recognises the most dominant structure and does not measure the extent to which church structures are used as non-salvageable capital.

Although the statistical results lend an encouraging degree of support to the model, several caveats are in order. First, the variables do not always exactly correspond to measures in the theory, the case of impressive structures being a clear example.

A second problem involves the coding process itself. Coders read texts about a culture and assign a number according to some prearranged scheme. Such a process is obviously subjective. Some researchers address this problem by employing multiple coders.

A final potential problem is that the Standard Cross-cultural Sample is not a random sample. As mentioned, cultures are chosen based on other criteria. This is a serious problem if the sample is biased in some way. For example, cultures are chosen because relatively complete data are available. This decision may exclude important classes of cultures not studied. Because of the emphasis of anthropological research, modern western industrial cultures may also be underrepresented.

\section{Conclusion}

The purpose of this article is to suggest that economics provides a fruitful vehicle for analysing religion and the church. We hypothesise that religions and churches serve the unintended function of reducing transactions costs. This is accomplished by establishing and enforcing a system of property rights. Property rights enforcement and other desired behaviour is encouraged by using the low-cost innovations of heaven and hell.

\section{Economic Theory of the Church}

Table I.

Multinomial Probit Results with Gods 
International Journal of Social Economics 16,7

14
Church survival also requires maintaining non-negative wealth. The church directly sells some products and funds others by using donations, the latter especially to overcome the difficulties of supporting production of public goods.

Churches provide a particular set of products in addition to property rights enforcement. The church provides entertainment and other forms of temporal bliss, facing competition from private markets. The church encourages good social behaviour (other than property rights enforcement) like wealth distribution and health standards. The church promises a deferred perpetuity in the form of eternal life and assures product quality by restricting its priesthood and employing nonsalvageable capital.

Multinomial probit analysis of variables from the Standard Cross-cultural Sample of the Human Relations Area Files supports some of the model's implications. Church influence increases and then decreases as a society becomes more complex. An increase in the number of religious sects increases church influence. Church influence is positively related to skill specialisation and by implication to specialised priestly skills. Efficient credit markets reduce interest rates, increasing the value of heaven and the cost of hell.

A first exploration always leaves undiscovered territory. This article is no exception. It presents an initial attempt to explain important features of the church and religion. It is also a first attempt to examine with economic theory the sort of cross-cultural data available in the Human Relations Area Files. Much work remains.

\section{References}

1. Smith, A., The Wealth of Nations, 9th ed., Strahan, A., Cadell, T. and Davies, W., London, 1799.

2. Tawney, R.H., Religion and the Rise of Capitalism, Murray, J. London, 1926.

3. Weber, M., The Protestant Ethic and the Spirit of Capitalism, trans, Parsons, T., Scribner, New York, 1958.

4. Meng, R. and Sentance, J., "Religion and the Determination of Earnings: Further Results", Canadian Journal of Economics, Vol. 17, August 1984, pp. 481-8.

5. Tomes, N., "'Religion and the Earnings Function", American Economic Review, Vol. 75, May 1985, pp. 245-50.

6. Ehrenberg, R.G., "Household Allocation of Time and Religiosity: Replication and Extension", Journal of Political Economy, Vol. 85, April 1977, pp. 415-24.

7. Long, S.H. and Settle, R.F., "Household Allocation of Time and Church Attendance: Some Additional Evidence", Journal of Political Economy, Vol. 85, April 1977, pp. 409-14.

8. Dixit, A. and Grossman, G., "Directly Unproductive Prophet-seeking Activities", American Economic Review, Vol. 74, December 1984, pp. 1087-8.

9. Posner, R.A., "The Law and Economics Movement", American Economic Review, Vol. 77, May 1987, pp. 1-13.

10. Stark, R. and Bainbridge, W.S., The Future of Religion; Secularization; Revival, and Cult Formation, University of California Press, Berkeley, 1985.

11. Becker, G.S., The Economic Approach to Human Behavior, University of Chicago Press, Chicago, 1976.

12. Alchian, A.A., "Uncertainty, Evolution, and Economic Theory", Journal of Political Economy, Vol. 58, June 1950, pp. 211-21. 
13. Cheung, S.N.S., "The Enforcement of Property Rights in Children and the Marriage Contract”, Economic Journal, Vol. 82, June 1972, pp. 641-57.

14. Posner, R.A., "A Theory of Primitive Society, with Special Reference to Law”, Journal of Law and Economics, Vol. 23, April 1980, pp. 1-53.

15. North, D.C. and Thomas, R.P., The Rise of the Western World; A New Economic History, Cambridge University Press, Cambridge, 1973.

16. Stigler, G.S., “The Economies of Scale”, Journal of Law and Economics, Vol. 1, Oct. 1958, pp. 54-71.

17. Homans, G.C., English Villagers of the Thirteenth Century, Russell and Russell, New York, 1960.

18. Davies, J.K., "Mormonism and the Socio-economic Order", International Journal of Social Economics, Vol. 13, 1986, pp. 64-79.

19. Hull, B.B., "Religion, Afterlife, and Property Rights in the High Middle Ages", forthcoming.

20. Darby, M.R. and Karni, E., "Free Competition and the Optimal Amount of Fraud", Journal of Law and Economics, Vol. 16, April 1973, pp. 67-88.

21. Nelson, P., “Advertising as Information”, Journal of Political Economy, Vol. 82, July/Aug. 1974, pp. 729-54; “Information and Consumer Behavior", Journal of Political Economy, Vol. 78, March/April 1970, pp. 311-29.

22. Klein, B. and Leffler, K.B., "The Role of Market Forces in Assuring Contractual Performance", Journal of Political Economy, Vol. 89, August 1981, pp. 615-42.

23. Murdock, G.P., Ethnographic Atlas, University of Pittsburgh Press, Pittsburgh, 1967.

24. Murdock, G.P. and White, D.R., "Standard Cross-Cultural Sample”, Ethnology, Vol. 8, October 1969, pp. 329-69.

25. Lagace, R.O., "'The HRAF Probability Sample: Retrospect and Prospect”, Behavior Science Research, Vol. 14, 1979, pp. 211-29.

26. Murdock, G.P. and Provost, C., "Measurement of Cultural Complexity", Ethnology, Vol. 12, Oct. 1973, pp. 379-92.

27. Murdock, G.P. and Morrow, D.O., "'Subsistence Economy and Supportive Practices: CrossCultural Codes 1”, Ethnology, Vol. 9, July 1970, pp. 302-30.

28. Murdock, G.P. and Wilson, S.F., "Settlement Patterns and Community Organization: CrossCultural Codes 3”, Ethnology, Vol. 11, July 1972, pp. 254-95. 